\title{
sciendo
}

\section{The influence of electron and gamma irradiation on the properties of starch:PVA films - the effect of irradiation dose}

Krystyna A. Cieśla ${ }^{0}$, Anna Abramowska

\begin{abstract}
The paper discusses the effect of ionizing radiation on the functional properties of the biodegradable starch:PVA films. The analysis is related to the possible use of the material for packing the products (particularly, food) that are predicted for radiation decontamination and to the potential modification of the material by radiation treatment. Our previous results have shown that the influence of ionizing radiation on the films' properties varied for the specific compositions (differing in starch:PVA ratio or the type of substrates) and depended on irradiation conditions. However, these studies considered only the irradiation performed in gamma chamber or in e-beam using a dose of $25 \mathrm{kGy}$. Therefore, the present study deals with the effect of the irradiations performed using various doses on the selected promising starch:PVA composition. The films characterized by starch:PVA weight ratio of 45:55 was obtained by solution casting and irradiated with fast electrons in air and with ${ }^{60} \mathrm{Co}$ gamma rays in nitrogen applying the doses of 5, 10, 20, 25, 30, 50, and $75 \mathrm{kGy}$. No regular dependence has been noticed between the composition of films (differing in the starch and PVA content) and the intensities of the particular bands in the UV-VIS DRS spectra after irradiation. The results indicated strong interaction of the starch and PVA components in the films and the occurrence of specific reactions in each composition upon irradiation. No special differences were observed between tensile strength and Young's modulus of the non-irradiated films characterized by the starch:PVA ratio equal to 45:55 and the samples irradiated using doses in the range of 5-75 kGy. Similarly, no differences were observed in both cases between the swelling capability of the non-irradiated and the irradiated films. However, it can be deduced that solubility in water increased when the radiation dose increased. The results show that using the doses till the range $25 \mathrm{kGy}$ does not cause an essential change of all the examined properties of the starch:PVA (45:55) films. Accordingly, starch:PVA (45:55) films might be considered suitable for packing food predicted for radiation decontamination.
\end{abstract}

Keywords: Starch:PVA film • Starch:poly(vinyl alcohol) • Gamma irradiation • Electron irradiation • UV-VIS - Mechanical properties $\bullet$ Swelling $\bullet$ Solubility

\section{K. A. Cieśla ${ }^{\bowtie}$}

Institute of Nuclear Chemistry and Technology

Dorodna 16 Str., 03-195 Warsaw, Poland

E-mail: k.ciesla@ichtj.waw.pl

A. Abramowska

Advanced Pharmaceutical Concepts (APS) Institute

Aleje Jerozolimskie 146c Str., 02-305 Warsaw, Poland

Received: 15 May 2020

Accepted: 28 August 2020

\section{Introduction}

The studies are mainly related to find new biodegradable materials for packaging the products (especially food) predicted for radiation decontamination/sterilization.

The materials based on biopolymers and synthetic biodegradable polymers involved a growing interest in the recent past due to the tendency for reducing the use of polyolefins, in particular for packaging purposes. Together with the development of new "green" technologies, this promotes environmental protection.

Natural polymers (polysaccharides or proteins) originated from renewable resources are relatively cheap and reveal a good film forming ability; however, manufacturing of the materials that might find practical application needs elaboration of special methodologies. Use of the systems composed of biopolymers and synthetic biodegradable polymers

0029-5922 @ 2021 The Author(s). Published by the Institute of Nuclear Chemistry and Technology.

This is an open access article under the CC BY-NC-ND 4.0 licence (http://creativecommons.org/licences/by-nc-nd/4.0/). 
is one of the possible strategies. Biodegradable and biocompatible materials are often intended for food packaging and edible packaging for food and pharmaceuticals.

Films and foams based on starch or PVA are already offered in the market for packaging purposes $[1,2]$. Starch:PVA composition is the other possible alternative [3-17]. It was already found that the films obtained in mixed starch:PVA system have advantages of both substrates while reducing their disadvantages $[3,6,8]$.

The development of sterilization/decontamination methods that apply radiation techniques causes the need for suitable packaging that retains good properties after irradiation [18-20]. The additional advantage of the radiation process consists of obtaining sterile packaging material. Thus, it becomes of high importance to determine the stability of both the packaging materials already present in the market and the newly developed materials under treatment with ionizing radiation. The possible improvement of the materials after irradiation might appear as additional merit of the "green" radiation processing.

The doses allowed for decontamination of food generally does not exceed $10 \mathrm{kGy}$ [21-23]. Such dose can be applied only for dry foodstuffs such as spices, herbs, mushrooms, whereas in the cases of "moist" food (e.g. chicken, shrimps, vegetables), doses applied are limited to 1-3 kGy. However, some special types of food (so-called durable food) can be treated with a sterilization dose of $25 \mathrm{kGy}$ [24]. Additionally, some products with a very special destination (i.e. for immunocompromised patients) can be treated with doses even in the range of $70 \mathrm{kGy}$ [24]. The other issue is application of high doses for radiation modification of foodstuffs [25-27]. High doses can be also applied for modifying the radiation of packaging material itself.

Accordingly to possible use for packing the products predicted for radiation treatment and an additional desirable modification of the material properties, an effect of irradiation should be tested. Mechanical properties and interaction of the films with moisture (especially swelling behaviour in water) appear as very important factors. It is worth mentioning that till now only a few studies deal with the effect of ionizing radiation on starch:PVA $[8,10$, 15-17], with more information on starch films or PVA-polysaccharide films [28-31], and that these studies were performed mainly concerning potential modification of the materials.

Our previous results have shown that it is possible to modify the functional properties of the starch:PVA films by modifying the films' composition (such as starch:PVA ratio or the type of substrates) and irradiation $[8,10]$. The influence of ionizing radiation on the particular films' properties are varied for the individual compositions $[8,10]$ and depending on irradiation conditions. However, this observation concerned only irradiation performed in gamma chamber or e-beam with the use of absorbed doses of $25 \mathrm{kGy}$.

Based on our previous results, it could also be concluded that using the composition characterized by starch:PVA ratio in the range from 50:50 to 40:60 enables manufacturing of the films (non-irradiated and irradiated) characterized by the best properties [8]. Moreover, these data show that mechanical properties were better in the case of starch:PVA (40:60) films, when starch:PVA (50:50) films revealed lower hydrophilicity. It was also noted that irradiations (performed with doses of $25 \mathrm{kGy}$ ) induce some increase in strength of the (50:50) films (improvement) while the decrease of this parameter was observed in the case of the films having the ratio 40:60. In contrast, the swelling parameter shows slight deterioration in the films with the ratio 50:50 (increase in swelling) but improvement in the films having the ratio 40:60 (decrease in swelling). However, all these films, non-irradiated and irradiated with gamma rays as well as with fast electrons, were characterized by properties that enable them to be used for packaging purposes.

Our present studies focused on the influence of the irradiation dose on the properties of the selected starch:PVA films. The composition with starch:PVA ratio equal to 45:55 was selected based on the previous data (see above) and the results of UV-VIS diffuse reflectance spectroscopy (DRS) that were carried out in the first stage of current work for the starch:PVA films characterized by various starch:PVA ratios. The effects of electron and gamma irradiation conducted with doses in the range of 5-75 kGy on the mechanical properties of the films and swelling in water were recognized.

\section{Experimental}

\section{Materials and irradiation}

\section{Materials}

Cornstarch (Sigma product S412) and poly(vinyl alcohol) PVA (Merck 8148941001) with a mean molecular mass of $145000 \mathrm{kDa}$, analytical grade glycerol (Chempur, Poland), and deionized water were applied. The solid starch specimen was pre-irradiated before the films' syntheses with a ${ }^{60} \mathrm{Co}$ gamma rays in the air with the absorbed dose of $10 \mathrm{kGy}$, applying a dose rate of $5.0 \mathrm{kGy}$ (see below).

\section{Films preparation}

A series of starch:PVA films were prepared by solution casting according to the procedure described in [8]. The films were characterized by starch:PVA ratios of 100:0, 80:20, 60:40, 50:50, 45:55, 40:60, 20:80, and 0:100 (PVA content equal to $0,20,40$, $50,55,60,80$, and $100 \%$, respectively) with the addition of glycerol (30\% in terms of the total polymer mass: altogether starch and PVA). PVA solution (1.64 wt\%) was obtained by heating accompanied with vigorous mixing in water for $4 \mathrm{~h}$ at $90^{\circ} \mathrm{C}$. The matter dispersion of starch and glycerol $(1.96 \%$ in terms of starch mass) was obtained by heating at $90^{\circ} \mathrm{C}$ for $40 \mathrm{~min}$. The starch was pre-irradiated with a dose of $10 \mathrm{kGy}$ in purpose to obtain starch gels 
with adequate concentration and low viscosity that enable to cast homogeneous films. Highly viscous gels obtained from the non-irradiated starch lead to the preparation of non-homogeneous films. Then, PVA solutions were introduced slowly into the gelatinized starch dispersions with continuous stirring and then heated subsequently for $1 \mathrm{~h}$. Afterward, the films were cast onto polystyrene Petri dishes, dried for $20 \mathrm{~h}$ in the heating chamber at $50^{\circ} \mathrm{C}$, then allowed to dry at ambient temperature, and finally cast from the substrate.

The films were conditioned before irradiation and testing at room temperature $\left(25^{\circ} \mathrm{C}\right)$ at a relative humidity of $43 \%$.

\section{Irradiation}

Irradiations of the films were carried out at ambient temperature with fast electrons in air and with gamma rays $\left({ }^{60} \mathrm{Co}\right)$ in nitrogen. Irradiation with fast electrons was carried out in the Elektronika 10/10 accelerator generating $10 \mathrm{MeV}$ electron beam at an average dose rate of approximately $3 \mathrm{kGy} / \mathrm{min}$ for the films packed in polyethylene bags. Gamma irradiation was realized in the gamma chamber GC 5000 applying a dose rate of $5.1 \mathrm{kGy} / \mathrm{h}$ for the films closed in a glass vessel.

The absorbed doses were equal to 5, 10, 15, 20, $25,30,50$, and $75 \mathrm{kGy}$.

\section{Methods}

\section{Diffuse reflectance spectroscopy}

DRS measurements were carried out applying Jasco V-670 spectrophotometer equipped with the reflection device (Model ISN-723 with an integrating sphere $60 \mathrm{~mm}$ ). Prior to the measurements, the films were irradiated with gamma rays in air at ambient temperature with the absorbed dose of $25 \mathrm{kGy}$. Measurements were taken for the individual irradiated films against the corresponding reference non-irradiated films.

\section{Mechanical properties}

Mechanical tests were performed using an Instron 5565 testing machine applying the ramp velocity of $20 \mathrm{~mm} / \mathrm{min}$. Tensile strength and Young's modulus values were determined based on eight measurements done for the pieces of material with dimensions ca. $60 \mathrm{~mm} \times 10 \mathrm{~mm}$ cut from separate films. The low value of Young's modulus shows high elasticity of films.

\section{Swelling behaviour}

Square pieces of the films (with dimensions of $10 \mathrm{~mm} \times 10 \mathrm{~mm}$ ) were weighed and immersed in distilled water for $24 \mathrm{~h}$ at $25^{\circ} \mathrm{C}$. Afterward, the films were drained using filter paper, reweighed, and dried at $110^{\circ} \mathrm{C}$ till constant mass ("dry mass") was achieved. The increase in the mass of the samples was related to the initial mass or the final "dry" mass of the sample. Swelling parameters (A and B) were determined as percentages ( $\mathrm{wt} \%$ ) applying the following formulas:

$$
\begin{aligned}
& \text { A: Swelling }(\text { initial })=100 \times\left(\mathrm{W}_{\mathrm{s}}-\mathrm{W}_{0}\right) / \mathrm{W}_{0} \\
& \text { B: Swelling }(\text { dry })=100 \times\left(\mathrm{W}_{\mathrm{s}}-\mathrm{W}_{\mathrm{d}}\right) / \mathrm{W}_{\mathrm{d}}
\end{aligned}
$$

where $\mathrm{W}_{0}, \mathrm{~W}_{\mathrm{s}}$, and $\mathrm{W}_{\mathrm{d}}$ mean the weight of the initial sample, the weight of the swollen sample (solid film with the captured water), and the weight of the dried sample (after the swelling experiment), respectively.

Moreover, total mass loss after the above swelling experiment was evaluated for each sample according to the formula:

$$
\text { Mass loss }=100 \times\left(\mathrm{W}_{0}-\mathrm{W}_{\mathrm{d}}\right) / \mathrm{W}_{0}
$$

Accordingly, the change (increase) in the solubility of the material after irradiation was calculated using the following formula:

$$
\text { Increase in solubility }=\Delta \mathrm{m}_{\mathrm{ir}}-\Delta \mathrm{m}_{0}
$$

where $\Delta \mathrm{m}_{\text {ir }}$ and $\Delta \mathrm{m}_{0}$ are average values of total mass loss determined in the case of the particular irradiated sample and the non-irradiated sample, respectively.

No effect of irradiation on the moisture content in the samples was observed. The moisture content in all the samples was similar $(11.35 \pm 0.85)$ and independent of the dose.

Three repetitions were done for each sample.

\section{Results and discussion}

\section{UV-VIS diffuse reflectance spectroscopy}

DRS spectra present the formation of various radiolysis products in the starch:PVA compositions differing in the starch and PVA contents (Fig. 1). No regular dependence was noticed when increasing or decreasing the content of PVA or starch in the films (Fig. 1) and the intensities of the particular bands in the patterns.

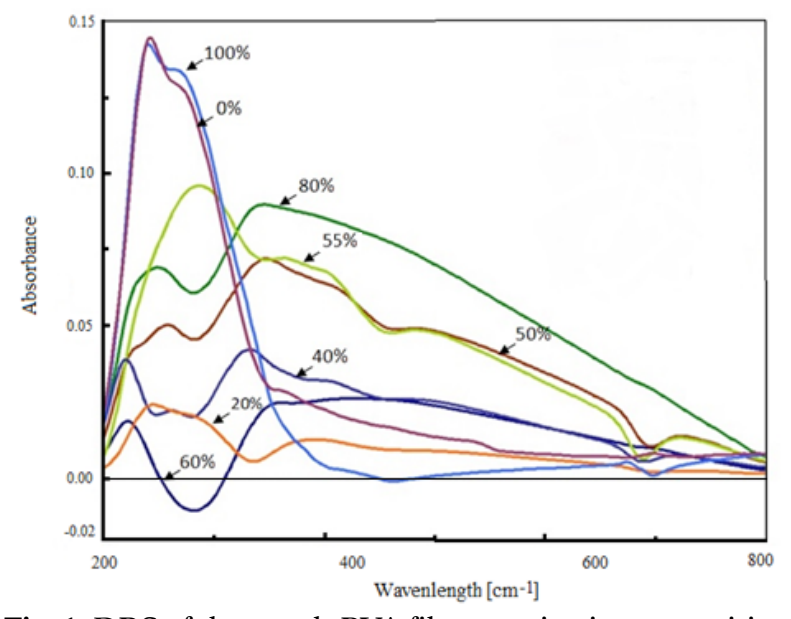

Fig. 1. DRS of the starch:PVA films varying in composition (shown in terms of PVA percentage). 
Similar radiolysis products were observed in the cases of the starch (100\%) and PVA (100\%) films. Two strong overlapping bands in these patterns (peaks at ca. 241-271 nm) were attributed to the presence of carbonyl and carboxyl groups $[32,33]$. The peaks at ca. $210 \mathrm{~nm}$ (Fig. 1) were assigned to the presence of peroxides and hydroxyperoxides $[34,35]$.

It is known that radiolysis of both components (starch and PVA) occurs with the formation of carbonyl and carboxyl derivatives. Sontag (2001) described the formation of various carbonyl products in polysaccharides due to substitution of some $\mathrm{OH}$ groups by $\mathrm{C}=\mathrm{O}$ groups [36]. This occurs due to the disruption of glycosidic bonds and ring-opening processes followed by the rearrangement of macromolecules [36, 37]. Conducting the processes in the presence of oxygen additionally leads to carboxylic products and probably increases the oxidation efficiency [38].

Głuszewski et al. [33] have suggested that the band with maximum at ca. $245 \mathrm{~nm}$ (Fig. 1) is related to vibrations of the $\mathrm{C}=\mathrm{O}$ groups placed in the middle of the polymer chain (ketone groups). Although assignments of the bands at the wide range of higher wavelengths (Fig. 1) is still not clarified, these bands might be connected to vibrations of the $\mathrm{C}=\mathrm{O}$ (and $\mathrm{COOH}$ ) groups in various positions (at and near the chain endings). Following the above-postulated allocation [33], it can be supposed that the increase in the intensities of these bands corresponds to an increase in chain ends resulting from the macromolecules scission. However, these bands can also originate due to the creation of $\mathrm{C}=\mathrm{C}$ bonds [39]. Akhter et al. [40] and El Savy et al. [41] described the processes of crosslinking PVA in the irradiated films via dehydroxylation and formation of $\mathrm{C}=\mathrm{C}$ linkages, in addition to the formation of $\mathrm{C}=\mathrm{O}$, $\mathrm{COOH}$, and $\mathrm{C}-\mathrm{O}-\mathrm{C}$ (ether) groups [42].

Differences in the profiles of the patterns recorded for the blended films concerning the starch and PVA films indicated strong interaction between these two components possibly leading to the formation of the specific network in the case of each composition.

In the case of the composition containing $20 \%$ of PVA, bands in a wide range of higher wavelengths appear (maximum at ca. $387 \mathrm{~nm}$ ) in addition to the pair of bands at $240-280 \mathrm{~nm}$. In the cases of compositions with PVA content of 50\% and $80 \%$, the relative intensities of the "ketone" peaks (at ca. $258 \mathrm{~nm}$ and ca. $249 \mathrm{~nm}$, respectively) was even lower as compared to the intensities of the bands at high wavelengths ( $348 \mathrm{~nm}$ and $343 \mathrm{~nm}$ ).

In the cases of the films containing $40 \%$ and $60 \%$ of PVA, only the bands in the region of high wavelength (shoulders with maxima at ca. 343-346 nm) were recorded in the range above ca. $240 \mathrm{~nm}$, with a lack of the band at 241-271 nm (or only a weak shoulder). However, simultaneously the bands at 200-212 nm (attributed to peroxides and hydroxyperoxides) were observed.

Occurrence of specific processes can be deduced in the case of films with PVA content of 55\% (starch:PVA ratio 45:55). DRS pattern of this composition differs from all the other patterns (including those of the films with $50 \%$ and $60 \%$ of PVA). It shows a strong band with the maximum at ca. $287 \mathrm{~nm}$ accompanied by the bands in the range of higher wavelengths (i.e. the shoulder at $360-460 \mathrm{~nm}$ ) and simultaneous lack of a band assigned to the peroxides/hydroxyperoxides. This composition was selected for present experiments.

It can be presumed, based on DRS results, that all radiolysis products formed in the cases of starch:PVA systems contain carbonyl (and possibly carboxyl) compounds; however, the efficiency of the formation of the $\mathrm{C}=\mathrm{O}$ (and $\mathrm{COOH}$ ) groups at a particular position in macromolecules differs for each composition.

\section{Mechanical properties}

The values of the tensile strength (Table 1) show an adequate strength of the initial and the irradiated films for packaging purposes. The low values of Young's modulus indicated a high elasticity of films (Table 1).

No effect of irradiation in e-beam (air) as well as in the gamma chamber (nitrogen) on tensile strength could be concluded after using doses in the range 5-75 kGy (Table 1). Simultaneously, no differences were observed between the Young's modulus values determined in the case of the samples irradiated using various doses and the respective non-irradi-

Table 1. Mechanical properties of the non-irradiated and the irradiated films

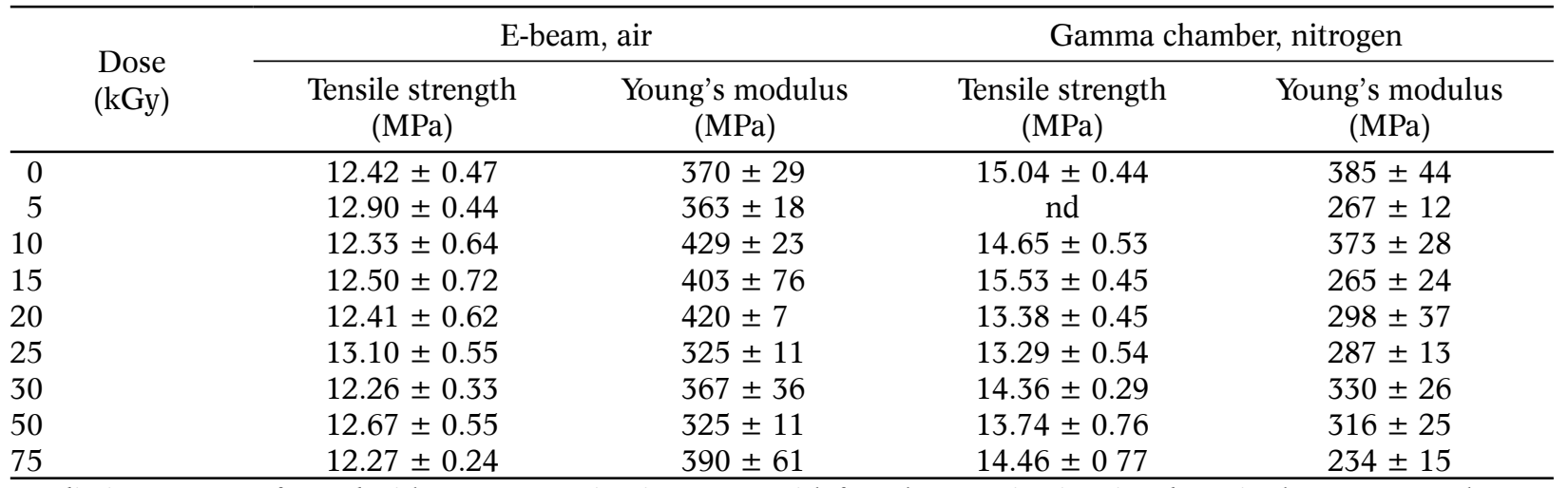

Irradiations were performed with gamma rays in nitrogen or with fast electrons in air using doses in the range 5-75 kGy. nd - not determined. 
ated reference samples (Table 1). All the irradiated samples were still characterized by a high elasticity.

\section{Swelling behaviour}

Swelling parameters A (Tables 2 and 3) were similar to those determined for starch:PVA systems by Mathew et al. and Tack et al. $[13,14]$ and somewhat lower compared to the results of Priya et al. [9]. Simultaneously, Tang et al. and Zhou et al. $[4,5]$ noticed a similar mass loss in the case of the starch:PVA after immersion in water at similar conditions.

No effect on both swelling parameters A and B was noticed after radiation in e-beam in the air with doses in the range of 5-75 kGy (Table 2). Simultaneously, the mass loss after immersion in water connected to the swelling experiment has increased after irradiation and was higher when the radiation dose increased (Table 2).

In the case of the sample irradiated with gamma rays no change of swelling parameter $B$ (related to the final "dry" mass) was observed (Table 3). However, a negligible decrease after irradiation could not be excluded at the higher doses for the swelling parameter A (related to the initial mass) (Table 3). At the same time, a similar increase in mass loss after the experiment was observed (increasing with a dose rise), as in the case of samples irradiated in the accelerator (Table 3).

Greater mass loss observed after swelling experiments in the case of the irradiated samples showed the increased solubility caused by irradiation (Tables
2 and 3). A similar increase in solubility occurred after treatment with fast electrons (air) as after the action of gamma rays (nitrogen) after the use of doses in the range 5-75 kGy. Simultaneously, it can be stated that irradiation with doses till ca. $25 \mathrm{kGy}$ causes a relatively low increase in the films' solubility.

\section{Conclusion}

Different radiolysis products can be observed in the starch:PVA compositions with respect to differing starch and PVA contents. No regular dependence has been noticed between the composition of the films and the intensities of the particular bands in the UV-VIS DRS after irradiation. The results indicated strong interaction of the starch and PVA components in the films and the occurrence of specific reactions in each composition upon irradiation.

No special differences were observed between mechanical properties (tensile strength and Young's modulus) of the non-irradiated films characterized by starch:PVA ratio equal to $45: 55$ and the films irradiated using doses in the range of 5-75 kGy. This concerns irradiation carried out both in e-beam under air and in gamma chamber under nitrogen. Similarly, no differences were observed between the swelling capability of the non-irradiated and the irradiated films. However, it can be deduced that solubility in water increased when the radiation dose increased.

It can be concluded that using doses in the range of $25 \mathrm{kGy}$ does not cause an essential change of all

Table 2. Swelling behaviour of the starch:PVA (45:55) films after irradiation performed with fast electrons in air using doses in the range 5-75 kGy: parameters of swelling A and B (related to the initial and the final mass, respectively), mass loss after the experiment and the increase in solubility caused by irradiation

\begin{tabular}{rcccc}
\hline $\begin{array}{c}\text { Dose } \\
(\mathrm{kGy})\end{array}$ & $\begin{array}{c}\text { Swelling A } \\
(\mathrm{wt} \%)\end{array}$ & $\begin{array}{c}\text { Swelling B } \\
(\mathrm{wt} \%)\end{array}$ & $\begin{array}{c}\text { Mass loss after } \\
\text { the experiment (wt\%) }\end{array}$ & $\begin{array}{c}\text { Increase } \\
\text { in solubility (wt\%) }\end{array}$ \\
\hline 0 & $196 \pm 5$ & $341 \pm 29$ & $27.46 \pm 1.00$ & 0.00 \\
5 & $185 \pm 3$ & $306 \pm 14$ & $28.93 \pm 0.86$ & 1.47 \\
10 & $213 \pm 4$ & $355 \pm 24$ & $29.65 \pm 1.31$ & 2.19 \\
15 & $208 \pm 9$ & $344 \pm 24$ & $30.60 \pm 1.76$ & 3.14 \\
20 & $183 \pm 3$ & $304 \pm 7$ & $30.13 \pm 1.25$ & 2.67 \\
30 & $199 \pm 5$ & $350 \pm 25$ & $31.56 \pm 0.83$ & 7.10 \\
50 & $208 \pm 6$ & $370 \pm 14$ & $34.73 \pm 1.95$ & 8.27 \\
75 & $183 \pm 16$ & $341 \pm 28$ & $35.73 \pm 2.13$ & 8.27 \\
\hline
\end{tabular}

Table 3. Swelling behaviour of the starch:PVA (45:55) films after irradiation with gamma rays performed in nitrogen using doses in the range 5-75 kGy: parameters of swelling A and B (related to the initial and the final mass, respectively), mass loss after the experiment and the increase in solubility caused by irradiation

\begin{tabular}{rcccc}
\hline $\begin{array}{c}\text { Dose } \\
(\mathrm{kGy})\end{array}$ & $\begin{array}{c}\text { Swelling A } \\
(\mathrm{wt} \%)\end{array}$ & $\begin{array}{c}\text { Swelling B } \\
(\mathrm{wt} \%)\end{array}$ & $\begin{array}{c}\text { Mass loss after } \\
\text { the experiment (wt\%) }\end{array}$ & $\begin{array}{c}\text { Increase } \\
\text { in solubility (wt\%) }\end{array}$ \\
\hline 0 & $231 \pm 2$ & $370 \pm 16$ & $29.40 \pm 1.93$ & 0.00 \\
5 & $229 \pm 8$ & $360 \pm 3$ & $31.66 \pm 2.47$ & 2.26 \\
10 & $225 \pm 7$ & $368 \pm 4$ & $32.98 \pm 1.68$ & 3.58 \\
15 & $212 \pm 9$ & $363 \pm 27$ & $32.12 \pm 4.86$ & 2.72 \\
20 & $214 \pm 4$ & $364 \pm 11$ & $32.70 \pm 0.89$ & 3.30 \\
25 & $217 \pm 3$ & $365 \pm 4$ & $32.11 \pm 1.44$ & 2.71 \\
30 & $225 \pm 9$ & $386 \pm 10$ & $33.82 \pm 0.79$ & 4.42 \\
50 & $218 \pm 17$ & $364 \pm 10$ & $35.13 \pm 2.54$ & 5.73 \\
75 & $200 \pm 15$ & $365 \pm 8$ & $37.67 \pm 2.28$ & 8.27 \\
\hline
\end{tabular}


the examined properties of the starch:PVA (45:55) films.

The results show that the starch:PVA (45:55) films might appear suitable for packing of food predicted for radiation decontamination.

Acknowledgments. The authors wish to thank Dr Wojciech Głuszewski for the help rendered in experiments on DRS spectroscopy.

\section{ORCID}

K. Cieśla (D) http://orcid.org/0000-0003-4511-5162

\section{References}

1. Voigt, H. -D., Gehring, M., Rom, C., Weiwad, D., Rapthel, I., Reichwald, K., \& Kakuschke, R. (1995) Patent WO96/17888 (PCT/DE1995/001732). Biodegradable thermoplastic materials and packaging containers made from them (by GMBH, R.J. Reynolds Tobacco GMBH).

2. Jimenez, A., Fabra, M. J., Talens P., \& Chiralt, A. (2012). Edible and biodegradable starch films: A review. Food Bioprocess Technol., 5, 2058-2076.

3. Ishigaki, T., Kawagoshi, Y., Ike, M., \& Fujita, M. (1999). Biodegradation of a polyvinyl-alcohol-starch blend plastic film. World J. Micr. Biot., 15, 321-327.

4. Tang, Sh., Peng, Z., Xiong, H., \& Tang, H. (2008). Effect of $\mathrm{SiO} 2$ on the performance of starch/polyvinyl alcohol blend films. Carbohydr. Polym., 72, 521-526.

5. Zhou, J., Ma, Y., Ren, L., Tong, Z., Liu, J., \& Xie, L. (2009). Preparation and characterization of surface crosslinked TPS/PVA blend films. Carbohydr. Polym., 76, 632-638.

6. Rahmat, A. R., Rahman, W. A., Sin, L. T., \& Yussuf, A. A. (2009). Approaches to improve compatibility of starch filled polymer system: A review. Mat. Sci. Eng. C, 29, 2370-2377.

7. Tang, X., \& Alavi, S. (2011). Recent advances in starch, polyvinyl alcohol based polymer blends, nanocomposites and biodegradability. Carbohydr. Polym., 85, 1-16.

8. Abramowska, A., Cieśla, K. A., Buczkowski, M. J., Nowicki, A., \& Głuszewski, W. J. (2015). The influence of ionizing radiation on the properties of starch-PVA films. Nukleonika, 60(3), 669-677. DOI:10.1515/nuka-2015-0088.

9. Priya, B., Gupta, V. K., Pathania, D., \& Singha, A. S. (2014). Synthesis, characterization and antibacterial activity of biodegradable starch/PVA composite films reinforced with cellulosic fibre. Carbohydr. Polym., 109, 171-179.

10. Cieśla, K., Abramowska, A., Boguski, J., \& Drewnik, J. (2017). The effect of PVA type and radiation treatment on the properties of starch-PVA films. Radiat. Phys. Chem., 141, 142-148. DOI:10.1016/jradphyschem.2017.06.015.

11. Cano, A. I., Cháfer, M., Chiralt, A., \& GonzalezMartinez, Ch. (2015). Physical and microstructural properties of biodegradable films based on pea starch and PVA. J. Food. Eng., 167, 59-64.
12. Aydin, A. A., \& Ilberg, V. (2016). Effect of different polyol-based plasticizers on thermal properties of polyvinyl alcohol: starch blends. Carbohydr. Polym., 136, 441-448.

13. Mathew, Sh., Jayakumar, A., Kumar, V. P., Mathew, J., \& Radhakrishnan, E. K. (2019). One-step synthesis of eco-friendly boiled rice starch blended polyvinylalcohol bionanocomposite films decorated with in situ generated silver nanoparticles for food packaging purpose. Int. J. Biol. Macromol., 139, 475-485.

14. Tak, H. -Y., Yun, Y. -H., Lee, Ch. -M., \& Yoon, S. -D. (2019). Sulindac imprinted mungbean starch/PVA biomaterial films as a transdermal drug delivery patch. Carbohydr. Polym., 208, 261-268.

15. Parvin, F., Khan, M., Saadat, A. H. M., Khan, M. A. H., Islam, J. M. M., Ahmed, M., \& Gafur, M. A. (2011). Preparation and characterization of gamma irradiated sugar containing starch/poly(vinyl alcohol)based blend films. J. Polym. Environ., 19, 1013-1022.

16. Senna, M. M., El-Shahat, H. A., \& El Naggar, A. W. M. (2011). Characterization of gamma irradiated plasticized starch/poly (vinyl alcohol) (PLST/PVA) blends and their application as protected edible materials. $J$. Polym. Res., 18, 763-771.

17. Naznin, M., Abedin, M. -Z., Khan, M. -A., \& Gafur, M. D. (2012). Influence of Acacia Catechu extracts and urea and gamma irradiation on the mechanical properties of starch/PVA-based material. International Scholarly Research Network (ISRN) Polymer Science, 2012, 348685(8p). DOI:10.5402/2012/348685.

18. Haji-Saeid, M., Sampa, M. H. O., \& Chmielewski, A. G. (2007). Radiation treatment for sterilization of packaging materials. Radiat. Phys. Chem., 76, 1535-1541.

19. Silvestre, C., Pezzuto, M., Duraccio, D., Marra, A., \& Cimmino, S. (2014). Exploiting nanotechnology and radiation technologies to develop new eco-sustainable nanomaterials for food packaging suitable for sterilization by irradiation. In Application processed nanomaterials in products from polymers for agricultural applications (pp. 99-104). Vienna: IAEA. (IAEA-TECDOC-1745).

20. Silvestre, C., Cimmino, S., Stoleru, E., \& Vasile, C. (2017). Application of radiation technology to food packaging. In Y. Sun \& A. G. Chmielewski (Eds.), Application of ionizing radiation in materials processing (pp. 461-484). Warsaw: Institute of Nuclear Chemistry and Technology.

21. Farkas, J. (1998). Irradiation as a method for decontaminating food. A review. Int. J. Food Microbiol., 44, 189-204.

22. Giroux, M., \& Lacroix, M. (1998). Nutritional adequacy of irradiated meat - a review. Food Res. Int., 31(4), 257-264.

23. Farkas, J. (2006). Irradiation for better foods. Trends Food Sci. Technol., 17, 148-152.

24. World Health Organization. (1995). International Consutative Group on Food Irradiation. Review of data of high dose (10-70 kGy) irradiation of food: report of a consultation, Karlsruhe, 29 August - 2 September 1994. WHO. (WHO/FNU/FOS/95.10).

25. Al-Kaisey, M. T., Alvan, A. -K. H., Mohammad, M. H., \& Saeed, A. H. (2003). Effect of gamma irradiation on anti-nutritional factors in broad bean. Radiat. Phys. Chem., 67, 493-496. 
26. Kim, J. -H., Kim, D. -H., Ahn, H. -J., Park, H. -J., \& Byun, M. W. (2005). Reduction of the biogenic amine contents in low salt-fermented soybean paste by gamma irradiation. Food Control, 16, 43-49.

27. Lee, J. -W., Kim, J. -H., Oh, S. -H., Byun, E. -H., Yook, H. -S., Kim, M. -R., Kim, K. -S., \& Byun, M. -W. (2008) Effect of gamma irradiation on viscosity reduction of cereal porridges for improving energy density. Radiat. Phys. Chem., 77, 352-365.

28. Cieśla, K. A., Nowicki, A., \& Buczkowski, M. J. (2010). Radiation modification of the functional properties of the edible films prepared using starch and starch-lipid system. Nukleonika, 55(2), 233-242.

29. Ibrahim, S. M. (2011). Characterization, mechanical, and thermal properties of gamma irradiated starch films reinforced with mineral clay. J. Appl. Polym. Sci., 119, 685-692.

30. Ryzhkova, A., Jarzak, U., Schäffer, A., Bämer, M., \& Swiderek, P. (2011). Modification of surface properties of thin polysaccharide films by low energy electron exposure. Carbohydr. Polym., 83, 608-615. DOI: 10.1016/j.carbpol.2010.08.029.

31. Stoica-Guzun, A., Stroescu, M., Jipa, I., Dobre, L., \& Zaharescu, T. (2013). Effect of $\gamma$ irradiation on poly (vinylalcohol) and bacterial cellulose composites used as packaging. Radiat. Phys. Chem., 84, 200-204.

32. Wang, Sh. -M., Huang, Q. -Z., \& Wang, Q. -Sh. (2005). Study on the synergetic degradation of chitosan with ultraviolet light and hydrogen peroxide. Carbohydr. Res., 340(6) 1143-1147.

33. Głuszewski, W., Boruc, B., Kubera, H., \& Abbasowa, D. (2015). The use of DRS and GC to studies the effects of ionizing radiation on paper artifacts. Nukleonika, 60(3), 665-668. DOI:10.1515/nuka2015-0090.

34. Zagórski, Z. P., \& Rafalski, A. (1998). Free radicals in irradiated unstabilized polypropylene, as seen by
DRS absorption-spectrophotometry. Radiat. Phys. Chem., 52, 257-260.

35. Milosavljevic, B. H., \& Thomas, J. K. (2001) Effects of the degree of hydrolysis on radiation induced reactions in the poly(vinyl alcohol)-poly(vinyl acetate) system. Radiat. Phys. Chem., 62, 3-10.

36. von Sontag, C. (2001). Carbohydrates. In: C. D. Jonah \& B. S. M. Rao (Eds.), Radiation chemistry. Present status and future trends (pp. 481-511). Amsterdam: Elsevier Sciences BV.

37. Relleve, L., Nagasawa, N., Luan, L. Q., Yagi, T., Aranilla, C., Abad, L., Kume, T., Yoshii, F., \& dela Rosa, A. (2005). Degradation of carrageenan by radiation. Polym. Degrad. Stabil., 87, 403-410. DOI:10.1016/j. polymdegradstab.2004.09.003.

38. Sharpatyi, V. A. (2003). Radiation chemistry of polysaccharides. 1. Mechanism of carbon monoxide and formic acid formation. High. Energ. Chem., 37(6), 369-372.

39. Cao, Sh., Zhang, H., Song, Y., Zhang, J., Yang, H., Jiang, L., \& Dan, Y. (2015). Investigation of polypyrrole/polyvinyl alcohol-titanium dioxide composite films for photo-catalytic applications. Appl. Surf. Sci., 342(1), 55-63.

40. Akhter, S., Allan, K., Buchanan, D., Cook, J. A., Campion, A., \& White, J. M. (1988). XPS and IR study of X-ray induced degradation of PVA polymer film. Appl. Surf. Sci., 35(2), 241-258. https://doi. org/10.1016/0169-4332(88)90053-0.

41. El-Sawy, N. M., El-Arnaouty, M. B., \& Abdel, G. (2010). $\gamma$-Irradiation effect on the non-cross-linked and cross-linked polyvinyl alcohol films. Polym. Plast. Technol. Eng., 49(2), 169-177.

42. Zainuddin, , Hill, D. J. T., \& Le, T. T. (2001). An ESR study on $\gamma$-irradiated poly(vinyl alcohol). Radiat. Phys. Chem., 62, 283-291. 